\title{
Serialización de la ficción televisiva: el género policiaco español y la narrativa compleja. Cadenas generalistas (1990-2010)*
}

\section{Anna Tous-Rovirosa ${ }^{1}$ \\ Tatiana Hidalgo-Marí2 Luís Fernando Morales-Morante ${ }^{3}$}

Recibido: 19/03/2019

Aprobado por pares: 02/07/2019
Enviado a pares: 19/03/2019

Aceptado: 19/07/2019

DOI: $10.5294 /$ pacla.2020.23.4.2

Para citar este artículo / to reference this article / para citar este artigo Tous-Rovirosa, A., Hidalgo-Mari, T. y Morales-Morante, F. (2020). Serialización de la ficción televisiva: el género policiaco español y la narrativa compleja. Cadenas generalistas (1990-2010). Palabra Clave, 23(4), e2342. https://doi.org/10.5294/pacla.2020.23.4.2

\section{Resumen}

Se estudian las 36 producciones seriales de género policiaco de las cadenas generalistas españolas (1990-2010) mediante un análisis narrativo, a partir de la hipótesis de que los cambios observados están relacionados con las influencias extranjeras y van a resultar determinantes para la narrativa serial de calidad contemporánea. Los objetivos de la investigación son determinar si se produce la evolución del procedimental a la cop-opera melancólica, y cómo se produce y qué interrelación se observa con la modernización del

\footnotetext{
Este artículo ha sido elaborado en el marco del proyecto "Historia de la programación y programas de ficción televisiva en España (cadenas de ámbito estatal): de la desregulación al apagón analógico, 1990-2010” (CSO201566260-C4-4-P), financiado por el Ministerio de Economía y Competitividad. Los datos de la producción de ficción española entre 2008 y 2010 proceden de los respectivos informes elaborados por el equipo español del Observatorio Iberoamericano de la Ficción Televisiva (Obitel).

$1 \bowtie$ http://orcid.org/0000-0003-4519-3793. Universidad Autónoma de Barcelona, España. anna.tous@uab.cat http://orcid.org/0000-0003-4599-5876. Universidad de Alicante, España. tatiana.hidalgo@ua.es

http://orcid.org/0000-0002-1839-3231. Universidad Autónoma de Barcelona, España. fernando.morales@uab.es
} 
relato televisivo. Entre los resultados, destaca que la estructura del procedimental deja de ser un impedimento para la serialización, que las analepsis como modo de resolución de los casos permiten que el procedimental y el serial se articulen, que el policiaco se mantenga como género en auge en la ficción televisiva contemporánea y proporcione numerosos títulos a las nuevas y viejas plataformas. Se ratifica la hipótesis planteada. La serialización del policiaco, la sofisticación en el uso de recursos narrativos y visuales, así como una clara influencia de las producciones extranjeras determinan la evolución del periodo analizado que se constata en la hibridación genérica y de formato, el subgénero forense y los recursos narrativos. La serialización coincide con el establecimiento del género en España en la segunda década analizada (2000-2010). La fragmentación visual de la trama acentúa una narrativa posmoderna. Se observa una narrativa en el policiaco cada vez más homogénea entre la ficción española y estadounidense, como La casa de papel (Netflix, 2017-). Las alteraciones temporales y la fragmentación del relato producen ficciones parecidas a un mosaico, y las transformaciones narrativas se usan para aumentar la vinculación de un espectador más activo.

\section{Palabras clave (Fuente: tesauro de la Unesco)}

Serialización; series televisivas; series de televisión; programa de televisión; ficción española; policiaco; narrativa compleja; España. 


\section{Serialized TV Fiction: The Spanish Crime Genre and Complex Narrative. Generalist Networks (1990-2010)*}

\section{Abstract}

This paper studies the 36 TV crime shows of the Spanish generalist channels (1990-2010) through a narrative analysis based on the hypothesis that the observed changes are related to foreign influences and will be decisive for contemporary serial narrative. It intends to determine if and how the procedural format has evolved into melancholic cop-opera and the interrelation with the modernization of TV stories. The results show that the structure of procedural drama no longer hinders serialization, that analepsis as a way of solving cases brings together procedural drama and series, and that cop-opera remains a genre on the rise in contemporary TV fiction, providing numerous titles to new and old platforms. These findings confirm the hypothesis suggested. The serialization of police drama, the sophistication in the use of narrative and visual resources, and the apparent influence of foreign productions determine the evolution of the analyzed period, as corroborated by generic and format hybridization, the forensic subgenre, and narrative resources. Serialization coincides with the establishment of the genre in Spain during the second decade analyzed (2000-2010). The visual fragmentation of the plot accentuates a postmodern narrative. Police drama reflects an increasingly homogeneous narrative between Spanish and American fiction, such as La casa de papel (Netflix, 2017-). Temporary alterations and story fragmentation produce mosaic-like fictions, and narrative transformations increase the engagement of a more active viewer.

\section{Keywords (Source: Unesco Thesaurus)}

Serialization; television programmes; television serials; Spanish fiction; crime fiction; police novel; complex narrative; Spain.

This article has been prepared within the framework of the project "Historia de la programación y programas de ficción televisiva en España (cadenas de ámbito estatal): de la desregulación al apagón analógico, 1990-2010” (CSO201566260-C4-4-P), funded by the Ministry of Economy and Competitiveness. The data on the production of Spanish fiction between 2008 and 2010 come from the respective reports prepared by the Spanish team of the Ibero-American Observatory of TV Fiction (Obitel). 


\section{Serialização da ficção televisiva: o gênero policial espanhol e a narrativa complexa. Canais generalistas (1990-2010)*}

\section{Resumo}

Estudam-se as 36 produções seriais de gênero policial dos canais generalistas espanhóis (1990-2010) mediante uma análise narrativa, a partir da hipótese de que as mudanças observadas estão relacionadas com as influências estrangeiras e vão resultar determinantes para a narrativa serial de qualidade contemporânea. Os objetivos da pesquisa são determinar se ocorre a evolução do processual à cop-opera melancólica, e como ocorre e que inter-relação se observa com a modernização do relato televisivo. Entre os resultados, destaca que a estrutura do processual deixa de ser um impedimento para a serialização, que as analepses como modo de resolução dos casos permitem que o processual e o serial se articulem, que o policial se mantenha como gênero em auge na ficção televisiva contemporânea e proporcione numerosos títulos às novas e às velhas plataformas. Ratifica-se a hipótese proposta. A serialização do policial, a sofisticação no uso de recursos narrativos e visuais, bem como uma clara influência das produções estrangeiras determinam a evolução do período analisado que se constata na hibridação genérica e de formato, o subgénero forense e os recursos narrativos. A serialização coincide com o estabelecimento do gênero na Espanha na segunda década analisada (20002010). A fragmentação visual da trama acentua uma narrativa pós-moderna. Observa-se uma narrativa no gênero policial cada vez mais homogênea entre a ficção espanhola e estadunidense, como La casa de papel (Netflix, 2017-). As alterações temporárias e a fragmentação do relato produzem ficções parecidas com um mosaico, e as transformações narrativas são usadas para aumentar a vinculação de um espectador mais ativo.

\section{Palavras-chave (Fonte: tesauro da Unesco)}

Serialização; séries televisivas; séries de televisão; programa de televisão; ficção espanhola; policial; narrativa complexa; Espanha.

\footnotetext{
* Este artigo foi elaborado no âmbito do projeto "História da programação e programas de ficção televisiva na Espanha (canais de âmbito estatal): da desregulamentação ao blecaute analógico, 1990-2010” (CSO2015-66260-C4-4-P), financiado pelo Ministério da Economia e Competitividade. Os dados da produção de ficção espanhola entre 2008 e 2010 procedem dos respectivos relatórios elaborados pela equipe espanhola do Observatório Ibero-americano da Ficção Televisiva (Obitel).
} 


\section{Introducción}

El género policiaco se ha considerado tradicionalmente el género episódico por excelencia. Se trata de un género de origen anglosajón literariamente (Colmeiro, 1994, p. 53) y de origen estadounidense televisivamente como género fundacional en la ficción seriada junto con el drama médico. Pero mientras que el hospitalario tiene proximidad con otro género fundacional, la soap opera, el policiaco ha permanecido durante décadas como drama episódico, sin continuidad en las tramas, sin que las relaciones personales fueran determinantes $\mathrm{o}$, incluso, sin que los personajes tuvieran una especial relevancia. El procedimental es paradigmático en este sentido (Cooke, 2001; Mittell, 2004; Von Mueller, 2014).

Partimos de la diferenciación entre formato como una tipología de producción de la industria televisiva (Buonanno, 2005; Chalaby, 2016; Jost, 2005), que puede ser equivalente a un programa (Gran Hermano, por ejemplo) o a las condiciones de producción de ciertos programas (serie, serial, miniserie, TV movie), y de género como un constructo idiosincrático, propio de una cultura, que permite a audiencia y emisor elaborar y reconocer un conjunto de programas (policiaco, médico, soap opera, político, aventuras, etc.), de modo que es la televisión un medio propicio para aumentar la competencia genérica del espectador y la creación de subgéneros (Fiske, 1987; Wolf, 1984).

Si bien el género que nos ocupa es el policiaco, analizamos también el subgénero forense. Colmeiro (1994) define la novela policiaca como "toda narración cuyo hilo conductor es la investigación de un hecho criminal, independientemente de su método, objetivo o resultado" (p.55), que consideramos plenamente aplicable a ese género televisivo. Se trata de un género complejo y prolífico que ha dado lugar a varios subgéneros. Aun compartiendo las precauciones del especialista en el policiaco y la novela negra, que prefiere hablar de "fórmulas narrativas" (véase su clasificación en Colmeiro, 1994, pp. 53-56) en relación con la clasificación de los subgéneros (en su caso, literarios) del policiaco, podemos afirmar que consta de las siguientes tipologías (Tous-Rovirosa, 2008, p. 265): 
- Según el método policiaco (analítico versus de acción)

- Según el maniqueísmo (refuerzo del statu quo o críticas con el sistema establecido)

- $\quad$ Según grupos e individuos (Zunzunegui y Zubillaga, 1998, p. 5)

- En función de la estética: estetización versus realismo, cinema verité

El policiaco puede tener un carácter formulaico, ${ }^{4}$ episódico o procedimental (referente a la resolución de un caso, policial, legal o forense). Las características narrativas del procedimental mediante sus tramas autoconclusivas permiten al espectador visionar los episodios con independencia unos de otros. ${ }^{5}$ Precisamente la consideración de Mittell (2009) de The Wire como "procedimental serializado" pone en tela de juicio esta última aseveración, pero, sobre todo, ejemplifica los cambios habidos en la narrativa audiovisual que aquí analizamos.

Partimos de la hipótesis de que los cambios observados en la narrativa analizada están relacionados con las influencias extranjeras recibidas y van a resultar determinantes para la narrativa serial de calidad hasta la actualidad. En este sentido, los objetivos de este artículo son determinar si se produce la evolución del procedimental a la cop-opera melancólica, en el género policiaco en las cadenas generalistas españolas (1990-2010), y cómo se produce y qué interrelación se observa con $s u$ contexto audiovisual y la modernización del relato televisivo.

\section{Marco teórico: hibridación de formato (serialización)}

La hibridación de formato o serialización es una cuestión que afecta a la narrativa audiovisual europea y estadounidense, y que tendrá su correlato en las ficciones de varios países. Dadas las circunstancias actuales en cuanto a consumo y circulación de contenidos audiovisuales, los cambios de las narraciones no se ciñen a un ámbito concreto, sino que viajan con suma fa-

4 Aunque el carácter formulaico no haya sido exclusivo del procedimental en televisión, sino que se puede extrapolar como un modo de funcionamiento de la industria televisiva (Newcomb, 1974, p. 22).

5 En el otro extremo, la soap opera se caracteriza por las tramas de continuidad, pero mediante un conjunto de estrategias narrativas (repeticiones, recordatorios) no es indispensable visionar todos los episodios precedentes para comprender la trama (véase McCarthy, 2001). 
cilidad (Buonanno, 2006). ${ }^{6}$ De hecho, es precisamente por ello (y por la preeminencia del policiaco como género televisivo estadounidense) que podemos estudiar el género en España en referencia a la serialidad de los Estados Unidos, y viceversa. La hibridación de formato que aquí nos ocupa consiste en la evolución de las series (formato episódico) a la serialidad (formato de continuidad), lo que Nelson (1997) denomina "flexi-narrativa". Innocenti y Pescatore (2011) también mencionan la hibridación de serie y serial: el cambio consiste en que "se añade un elemento de progresión temporal y de parcial apertura narrativa ausente en la fórmula tradicional" (p.34).

Por ejemplo, la superserie hispanoamericana (como El reino de los cielos, Telemundo, 2013-) se caracteriza por el aumento de temporadas, un supuesto incremento de la calidad, el protagonismo masculino y la acción, desapareciendo el melodrama como eje, aunque los problemas sociales persistan y siga siendo una telenovela (Piñón y Flores, 2017, pp. 257-287), en un consumo televisivo preminentemente femenino. El formato de las superseries es un ejemplo que ilustra que la serialización tiene consecuencias ideológicas y estéticas, como afirman Allen y Berg (2014, p. 2) a propósito de la soap opera, así como Lindner (2014): "La serialización no es solo una lógica de producción sino también una forma narrativa que desempeña un importante trabajo cultural con consecuencias ideológicas y estéticas profundas" (p. 3).

El policiaco permanece en la ficción contemporánea, con auges especialmente significativos como la ficción nórdica (cfr. Agger 2016), porque se adapta a la serialización (Klinger, 2018, p. 519) que es actualmente el formato en boga y que desde la tercera edad dorada de la TV se equipara con la calidad televisiva, además del rendimiento económico que tiene como producto en la industria televisiva ("mercantilización del ocio", en palabras de Allen y Berg, 2014, p. 2), con nuevas plataformas audiovisuales, crecientes en número y necesitadas de contenido. Ratificamos que se

6 Por otra parte, la globalización y la actual estrategia de plataformas audiovisuales de contenido como Netflix (fomentar "producciones propias" con los nuevos países donde se implanta) se suma a la fuerza que tienen las narraciones de carácter universal para llegar a públicos de otros países y, con ellas, las correspondientes estrategias narrativas. Además de Occidente, algunos ejemplos los encontramos en Brasil, Hispanoamérica, Turquía, Islandia y Australia. 
trata de un fenómeno que se produce a nivel internacional. Tal como afirma Cascajosa (2018),

el hecho de que las tres series analizadas (El Príncipe, Mar de plástico y Perdóname, Señor) hayan tenido saludables ventas internacionales en un momento en el que ello se ha convertido en un objetivo esencial para la ficción española muestra la viabilidad comercial de este nuevo sentido del lugar de la ficción televisiva de género criminal. (p. 9)

Klinger (2018, p. 519) relaciona los cambios tecnológicos y de consumo con los cambios habidos en la serialidad, y vincula la televisión de calidad con la serialización, tal como destacaron Newman \& Levine (2012) y Mittell (2015). ${ }^{7}$ Una diferencia relevante con el pasado es que las temporadas cada vez son más cortas y la narrativa más larga. Tal como constatamos en esta investigación, la estructura del procedimental deja de ser un impedimento para la serialización:

A la vez que contiene otros aspectos de la era post-network, el drama criminal de importación ofrece un conocido modo de serialidad para los espectadores estadounidenses: enfoque a la resolución del misterio, varias temporadas, arcos narrativos compactos que ofrecen complejidad narrativa y una finalización de la temporada 0 una justificación para la continuidad de la historia. (Klinger, 2018, p. 512)

Los procedimentales no tratan nunca sobre un personaje sino sobre la resolución de un caso, a diferencia del detectivesco. Sherlock Holmes y House $^{8}$ serían dos buenos ejemplos de ello. El procedimental valida el trabajo en equipo, de personas al servicio de una institución. Puede contener personajes geniales, outsiders o fuera de la ley (Casetti, 1991, p. 181) que son recurrentes del género, pero nunca versa sobre un personaje sino sobre cómo el sistema defiende el orden y se enfrenta el crimen, ${ }^{9}$ también mediante la confianza en la justicia y la ciencia. En la evolución del género en la ficción estadounidense, el retrato realista y obstinado en reforzar el sta-

7 Buonanno (2018) reflexiona sobre la (supuesta) relación entre las características de televisión de calidad y las nuevas plataformas audiovisuales, especialmente Netflix.

8 Vilches (2008, p. 290) destaca la influencia del protagonista de House en el auge de personajes con carisma, profundidad psicológica, con mayor importancia en las tramas, mientras que los neutros caen en desuso.

9 De ahí, añadimos, que suela coincidir con la defensa del statu quo vigente, como la emblemática Dragnet (NBC, 19511959) y la contemporánea CSI, por ejemplo. Dragnet es un procedimental estadounidense fundamental para comprender el policiaco de los Estados Unidos. Goza de continuidad en varias formas hasta 2004. 
tu quo vigente ha dado paso a la cop-opera (Von Mueller, 2014). La permanencia exitosa del procedimental en la denominada era del drama, tercera edad dorada de la TV o, más recientemente, narrativa compleja, complex $T V$ (Mittell 2006, 2015) y peak TV (Landgraff, citado por Littleton 2015), sumada al retrato psicológico de los protagonistas y a la desesperanza en la lucha contra el crimen, ${ }^{10}$ ha terminado produciendo "no grandes detectives sino trágicos", y la serialización de este formato llegando a ser melancholic cop-operas en las que los agentes del bien no tienen esperanzas de ganar (Von Mueller, 2014, p. 107), retomando y reforzando una de las tipologías del género, la crítica con el sistema establecido, tal como afirmaban Zunzunegui y Zubillaga (1988) en referencia a Canción triste de Hill Street (Hill Street Blues, NBC, 1981-1987), en la que "la policía no tiene por finalidad resolver los problemas reales de la sociedad. Porque son insolubles" (p. 17).

Dos formatos tradicionalmente opuestos, el serial abierto y el procedimental, se fusionan en la ficción televisiva contemporánea. El espectador no solo adquiere competencia genérica, sino también de formato:

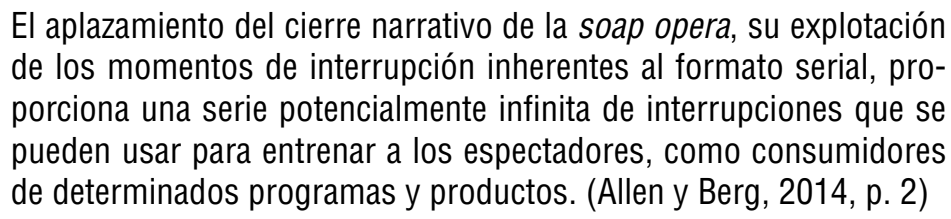

La posmodernidad (Lyotard, 1979, 1993) se caracteriza por la pérdida de fe en verdades "absolutas", por la disolución de estilos y géneros, la intertextualidad y la propuesta de textos abiertos. Supone el fin de las grandes creencias, de las grandes ideas (Lyon, 1994/1996) y de los "metarrelatos" (Lyotard, 1979). La plasmación en la narrativa (audiovisual o no) se produce en forma de fragmentariedad de los relatos (Duch, 1995; González Requena, 1992; Imbert, 2003; Magris, 1984), de bricolage (Lyotard, 1993, p. 171), y conduce a un "pastiche" conformado por inserts (Casetti \& Odin, 1990). La hibridación genérica es, por tanto, una de las consecuencias de los cambios ocasionados a causa de la posmodernidad, de la mano de la fragmentariedad del discurso (Imbert, 2005; Tous-Rovirosa, 2008).

10 Previamente observada en el drama médico (cfr. Jacobs, 2001, 2003). 
La serialización ha sido estudiada como fenómeno por parte de los investigadores españoles, quienes han analizado tanto producciones extranjeras como propias. Gubern (1999) es uno de los pioneros así como Paz Gago (2004). Más recientemente cabe destacar las aportaciones de Balló y Pérez (2005), Cascajosa (2015 y 2018), García (2016), Garin (2017), Innocenti y Pescatore (2011), Pérez (2011), Pérez y Garin (2013) y Raya (2016). Esta línea de investigación contiene unas ramificaciones que vinculan la narrativa audiovisual con lo lúdico (Mittell, 2009), los videojuegos (Cuadrado, 2016) y la narrativa transmedia, como propone acertadamente García (2017).

\section{Metodología y muestra}

Para dilucidar los cambios narrativos, de formato y de género de las producciones analizadas, consideramos que la narratología (Bal, 2005; Genette, 1972) y su aplicación a la ficción televisiva, la narrativa audiovisual (GalánFajardo y Rueda-Laffond, 2011; Rincón, 2011; Wallace, 2001), permiten diferenciar y delimitar los procesos que afectan las series analizadas (tabla 1). Se analizaron los dos primeros y los dos últimos episodios de cada temporada de los 36 títulos de género policiaco que se emitieron en las cadenas generalistas españolas entre 1990 y 2010 , de modo que se pudo estudiar el establecimiento del relato en los iniciales y los cambios propios del género en los finales, así como los elementos estructurales y narrativos de interés para esta investigación.

\section{Tabla 1. Lista de producciones policiacas españolas por formato (1990-2010)}

\begin{tabular}{|l|c|c|}
\hline \multicolumn{2}{|c|}{ Series } \\
\hline Título & Cadena & Años \\
\hline Eurocops & La 2 & $1988-1992$ \\
\hline Brigada central & TVE 1 & $1989-1992$ \\
\hline Pájaro en una tormenta & TVE 1 & 1990 \\
\hline Alta tensión & La 2 & 1993 \\
\hline Petra Delicado & Tele 5 & 1999 \\
\hline Pepe Carvalho & Tele 5 & $1999-2000$ \\
\hline
\end{tabular}




\begin{tabular}{|c|c|c|}
\hline El comisario & Tele 5 & 1999-2009 \\
\hline Antivicio & Antena 3 & 2000 \\
\hline Policías: en el corazón de la calle & Antena 3 & $2000-2003$ \\
\hline Robles, investigador & TVE 1 & $2000-2001$ \\
\hline Mi teniente & TVE 1 & 2001 \\
\hline Lobos & Antena 3 & 2005 \\
\hline Los hombres de Paco & Antena 3 & $2005-2010$ \\
\hline RIS Científica & Tele 5 & 2007 \\
\hline Génesis: en la mente del asesino & Cuatro & 2006-2007 \\
\hline Cuenta atrás & Cuatro & $2007-2008$ \\
\hline Desaparecida & TVE 1 & $2007-2008$ \\
\hline Hermanos $y$ detectives & Tele 5 & $2007-2009$ \\
\hline Cazadores de hombres & Antena 3 & 2008 \\
\hline Guante blanco & TVE 1 & 2008 \\
\hline UCO & TVE 1 & 2008-2009 \\
\hline La chica de ayer & Antena 3 & 2009 \\
\hline Los misterios de Laura & TVE 1 & 2009-2014 \\
\hline \multicolumn{3}{|c|}{ Serial } \\
\hline Suárez y Mariscal: caso cerrado & Cuatro & 2005 \\
\hline \multicolumn{3}{|c|}{$\begin{array}{c}\text { Producciones unitarias } \\
\text { Miniseries }\end{array}$} \\
\hline Camino de Santiago & Antena 3 & 1999 \\
\hline Soy el solitario & Antena 3 & 2008 \\
\hline Fago & TVE 1 & 2008 \\
\hline 48 horas & Antena 3 & 2008 \\
\hline El caso Wanninkhof & TVE 1 & 2008 \\
\hline Una bala para el rey & Antena 3 & 2009 \\
\hline El Bloke: coslada cero & TVE 1 & 2009 \\
\hline \multicolumn{3}{|c|}{ TV movies } \\
\hline Mateo y Rafa & Antena 3 & 2000 \\
\hline Ferrery Ruso & Antena 3 & 2000 \\
\hline Lucía y Carlos & Antena 3 & 2001 \\
\hline Snuff & Antena 3 & 2003 \\
\hline El crimen de los marqueses de Urquijo & TVE 1 & $2009-2014$ \\
\hline
\end{tabular}

Fuente: elaboración propia. 
Tal como hace Mittell (2015) al analizar la narrativa compleja de la televisión, consideramos que nos encontramos ante un modo de narración distinto, siguiendo la terminología de Bordwell (1996), y nos proponemos detallar en qué consiste exactamente, analizando las distintas modalidades de fragmentación del relato (tabla 2).

\section{Tabla 2. Modalidades narrativas de fragmentación del relato.}

\begin{tabular}{|c|c|c|c|}
\hline $\begin{array}{c}\text { Historia (pilares de la } \\
\text { narratividad) }\end{array}$ & Narración & $\begin{array}{c}\text { Discurso (formas de } \\
\text { expresión de la historia, } \\
\text { tipología de inserts) }\end{array}$ & Estructura (desenlace) \\
\hline $\begin{array}{c}\text { Tiempo (alteraciones cronológicas } \\
\text { como analepsis y prolepsis) }\end{array}$ & Contrapunto & $\begin{array}{c}\text { Imágenes grabadas, } \\
\text { recreaciones informáticas }\end{array}$ & Cliff-hanger \\
\hline Espacio (exteriores/interiores) & Técnica Rashomon & Fragmentos de videoclip & Estructura circular \\
\hline Personajes & In media res & $\begin{array}{c}\text { Efectos especiales, travelling } \\
\text { circular, pantalla partida }\end{array}$ & $\begin{array}{c}\text { Resolución del caso } \\
\text { (procedimental) }\end{array}$ \\
\hline
\end{tabular}

Fuente: elaboración propia según Bal (2005) y Genette (1972).

También se observará el grado de hibridación genérica de las narraciones y las influencias extranjeras en la medida en que están relacionadas con la serialización aquí estudiada.

\section{Resultados ${ }^{11}$}

En cuanto a la tipología genérica del periodo analizado, hay un claro predominio del policiaco dramático. Las series más exitosas fueron El comisario (Tele 5, 1999-2009), con más de 4 millones de espectadores y un 24,5\% de share; Policías: en el corazón de la calle (Antena 3, 2000-2003), con 3295000 espectadores y un $22 \%$ de share; y Los hombres de Paco (Antena 3, 20052010), con 3178000 espectadores y un 18,9\% de share. Estas tres series conjugaron acción policial y tramas personales, y fueron las más exitosas y longevas del periodo, especialmente El comisario que se mantuvo diez años en emisión. Los formatos de las 36 producciones fueron los siguientes: 23 series, 7 miniseries, 5 TV movies y 1 serial. Cabe destacar que Suárez y Mariscal: caso cerrado fue el único serial y un importante fracaso de audiencia.

11 Los datos de audiencia proporcionados provienen del trabajo realizado en el marco del proyecto en que se inscribe. 
El género policiaco en las cadenas españolas es incipiente entre 1990 y 2000 hasta el cambio de milenio, con la llegada de El comisario (Tele 5, 1999-2009). Es en esta segunda década (2000-2010) cuando se produce el auge del policiaco (cfr. Vilches et al., 2000). Romero (2015) menciona como causas del sorpasso de este género los realities policiacos de la década de los noventa y el impulso a las producciones de miniseries, telefilmes y series por la Ley 7/2010, de 31 de marzo, general de la comunicación audiovisual, a las que añadimos la emisión en las cadenas nacionales de ficciones extranjeras de género policiaco con éxito de audiencia de la época. Con la finalización del monopolio de RTVE en España, en 1989, ninguna de las recién estrenadas cadenas privadas (Antena 3 y Tele 5) apostó por este género. TVE combina adaptaciones literarias con coproducciones y series de producción propia: Brigada Central (TVE 1, 1989-1992), Pájaro en una tormenta (TVE 1, 1990), Petra Delicado (Tele 5, 1999), mientras que en la ficción triunfa la comedia y TVE, Antena 3 y Tele 5 se "disputan” los realities policiacos. El policiaco se consolida entre 2000 y 2005 (El comisario, Policías, Los hombres de Paco), pero es en el último quinquenio analizado (2005-2010) cuando se emiten el $50 \%$ de las producciones del periodo, entre ellas Cuenta atrás (Cuatro, 2007-2008). Desaparecida (TVE 1, 2007-2008), Hermanos y detectives (Tele 5, 2007-2009), Guante blanco (TVE 1, 2008), Soy el solitario (Antena 3, 2008), UCO (TVE 1, 20082009), La chica de ayer (Antena 3, 2009), Los misterios de Laura (TVE 1, 2009-2014) y una no menos significativa cantidad de producciones unitarias (tabla 1).

Entre 2000 y 2004, se produce un giro en la narrativa de la ficción analizada: las producciones anteriores a esa fecha (Brigada Central, Eurocops [La 2, 1988-1992], Pájaro en una tormenta, Alta tensión [La 2, 1993], Petra Delicado, Pepe Carvalho [Tele 5, 1999-2000]) presentan planteamientos episódicos, procedimentales, con tramas personales significativas. El policiaco español no ha presentado el carácter formulaico de otras latitudes. Las primeras series fueron episódicas y procedimentales, aunque ya contenían elementos de serialización. El texto televisivo se construye mediante tramas entrelazadas y alternancia entre las vidas privadas de los protagonistas y la acción policial. La narración es más descriptiva y pausada, y la cantidad de 
tramas entrelazadas es menor, y dota de menos dinamismo a las producciones. En Petra Delicado, todavía abunda el telling (narración de hechos por parte de los personajes) en detrimento del showing.

La transformación del relato televisivo en el periodo analizado radica en el aumento de la fragmentación del relato. El tiempo de la historia y el espacio se fragmentan. Los inserts aumentan y progresivamente van trufando el relato, cuyos desenlaces también varían. A partir de Antivicio (2000) y hacia la mitad de El comisario (2004), se constatan cambios fundamentales en la narrativa audiovisual (fragmentación, inserts, aumento de analepsis), la mayoría de los cuales permanecerá en la narrativa audiovisual contemporánea.

Esta fragmentación afecta de modo desigual las producciones españolas analizadas y contribuye a su caracterización. Cuanto más sofisticada y moderna es una producción, más recursos incorpora, pero sorprende la incorporación de dichos recursos por parte de un producto que podemos calificar de mainstream como El comisario, que nos indica el grado de popularización de estos cambios. La fragmentación del relato mediante la incorporación del insert tiene la función de aumentar la agilidad del relato, combatir el zapping y elaborar un relato entramado. El resultado puede ser una estructura arquitectónica parecida a la novela artúrica (Cirlot, 2005): un mosaico de tramas entrelazadas, comparable a un collage. Según Garin (2017), "los aspectos clave de la llamada complejidad televisiva se dieron antes en otros contextos seriales como la narrativa artúrica o el manga" (p. 29). Previamente habían analizado esta cuestión Tous-Rovirosa (2008) y Pérez \& Garin (2013). La combinatoria de fragmentos ya había sido anunciada por Vernet (1980). García-Fanlo (2017) describe "la compleja desfragmentación tanto espacial como temporal del relato" (p. 82) en el caso de Perdidos (Lost, ABC, 2004-2010), por ejemplo. Tous-Rovirosa (2008) y Crisóstomo \& Ros (2014) han analizado la importancia de las anagnórisis en esta misma serie. De hecho, a partir de Perdidos se produce un "despliegue" de la utilización de esta figura retórica, también utilizada en el cómic como recurso que contribuye a fragmentar el relato televisivo (como se observa posteriormente en producciones como Dextery Orange is the New 
Black). La explotación de esta figura tiene distintas funcionalidades, pero el reconocimiento de la verdadera identidad de un personaje se encuentra presente en el policiaco analizado, y la analepsis (vida anterior de los personajes) contribuye a justificar el relato.

Enumeramos a continuación las principales características y su incidencia en la evolución del género:

- Fragmentación temporal (articulación del relato en distintos planos temporales)

- Fragmentación espacial

- Narración

- Inserts en la estructura enunciativa

- Cambios narrativos en el desenlace

\section{Fragmentación temporal}

El tiempo de la historia (orden cronológico de los acontecimientos) queda interrumpida por las anacronías temporales (analepsis o prolepsis). El enigma, la resolución del caso, se articula con la investigación policial y configura un relato fragmentado que incorpora una amplia tipología de inserts narrativos, espaciales y temporales.

La historia contiene los elementos de temporalidad del relato y los espaciales (Bal, 2005). Las alteraciones cronológicas se sitúan en este plano: las analepsis o retroversiones, y las prolepsis o anticipaciones. Mittell (2015) sitúa las analepsis en el tiempo del discurso:

Las tramas de misterio a menudo juegan con el tiempo del discurso para crear suspense con respecto a acontecimientos del pasado, mientras que no es hasta el final de la narración cuando se revela el hecho instigador que diegéticamente ocurrió al principio de la historia. Muchas narrativas complejas juegan con la cronología para involucrar a los espectadores y animarlos a intentar diseccionar activamente la historia. (p. 26)

Es una característica del policiaco, que se puede observar en muchas de las producciones del periodo analizado, el uso creciente de las analepsis (flashbacks) para mostrar "qué ocurrió" (whodunnit cuando el enigma es el 
motor de la narración) versus howdunnit en las que el cómo se hizo el vector fundamental, más propio de las forenses. También observamos como tendencia en auge que, si un caso es complejo o se presenta como tal, se muestran distintas versiones de su resolución.

El recurso de las analepsis deviene una invariante en el policiaco. A diferencia de otros géneros televisivos, no necesitan justificación, ya que las analepsis están planteadas para complementar la versión de los sospechosos o víctimas, y el relato para la resolución del caso, además de fragmentarlo.

El aumento del recurso provoca la especialización, y las analepsis en el policiaco analizado pueden ser informativas, emotivas o referidas a la vida privada de los personajes, en función del grado de serialización del producto. Por ejemplo, Los hombres de Paco contiene analepsis referidas a la intimidad de los protagonistas. ${ }^{12}$ En Desaparecida, se pueden observar las analepsis emotivas (recuerdos familiares y de amigos de Patricia Mar$\cos [\text { Beatriz Ayuso }]^{13}$ ) y analepsis informativas de resolución del caso propias del género, que se van sucediendo hasta que el culpable confiesa, en el último episodio mediante dos analepsis de resolución (Desaparecida, cap. 13, "El último día").

Las analepsis suelen diferenciarse del relato principal mediante un color o tono distintos, acentuando la mencionada fragmentación, como sucede en Cuenta atrás (1.2, "Océano Atlántico, aguas jurisdiccionales de Togo, 07:14 horas"), El comisario, Hermanos y detectives, Soy el solitario, UCO, La chica de ayer. En esta serie, actúan como marca diegética, para diferenciar el pasado con un tono amarillento (1977), opuesto al grado cero del presente (2009). La diferenciación de las analepsis con la ayuda del color es un recurso que ya habíamos podido observar en CSI, de la mano del director Danny Cannon (Tous-Rovirosa, 2008, pp. 239-240). En El comisario, a menudo se contraponen las versiones de los acusados en la recta final del epi-

12 De orden sentimental en Los hombres de Paco, 1.1. "La suerte"; Los hombres de Paco, 2.8. "Sin tregua”. O para resaltar la belleza y juventud de Sara (Michelle Jenner) en Los hombres de Paco, 5.1. "El click".

13 Por ejemplo, cuando el padre de Patricia recuerda que de niña le regaló un cenicero para el Día del Padre (Desaparecida, cap. 3. "Día 11"). O la analepsis emotiva final mediante la cual el padre se despide de su hija (Desaparecida, cap. 13, "El último día”). 
sodio, intercalando las dos versiones y añadiendo analepsis de lo sucedido, también como en CSI. En ocasiones puntuales, la analepsis posee una significación específica, como el relato de Povedilla (Carlos Santos) en Los hombres de Paco acerca de los abusos a que fue sometido. Con la intercalación de la analepsis de los abusos, a las que se añaden efectos especiales, y su cita amorosa con Rita, se explicita su incapacidad de seguir hacia delante sin resolver su pasado, como afortunadamente para el personaje acaba sucediendo (Los hombres de Paco, 5.12, "Vivir tapando"). Para decirlo en palabras de $\mathrm{Bal}$ (2005): "Los elementos de la fábula son los mismos, pero su significado ha cambiado. El pasado recibe un sentido distinto” (p. 91).

Los saltos temporales oscilan entre la anacronía puntual (Bal, 2005, p. 92) de Los misterios de Laura y la anacronía durativa de La chica de ayer (serie que se construye a partir de los saltos temporales), en consonancia con la tipología de la producción. El único caso de ausencia de analepsis en las producciones posteriores a 2005, del conjunto de producciones analizadas, es El Bloke: coslada cero (TVE 1,2009) y, de modo mucho más puntual, UCO (segunda parte, "Asedio").

Habitualmente en las ficciones analizadas las analepsis son homodiegéticas internas completivas (Genette, 1972, pp. 90-92). De acuerdo con el género policial, se produce un nexo entre la analepsis y la sanción ${ }^{14}$ (subordinación narrativa de las analepsis a la resolución de las intrigas), de modo que las analepsis no pueden ser externas ni heterodiegéticas, sino homodiegéticas completivas, ya que "incluyen los segmentos retrospectivos que se llenan tras ocupar una laguna anterior del relato” (p. 92).

Las lagunas pueden ser de elisión diacrónica o de omisión de elementos constitutivos de la situación, de modo que es la investigación policiaca "el relato principal" (Genette, 1972). La resolución del caso depende de las analepsis, de ahí el carácter completivo de esta figura retórica en el policiaco. Este es el mecanismo que permite que el procedimental y el serial se articulen, que el policiaco se mantenga como género en auge en la ficción televisiva contemporánea y proporcione títulos a las nuevas y viejas plataformas.

14 “Sanción" entendida como fase final, resolución del esquema narrativo canónico (véase Greimas, 1979). 
La utilización de la analepsis y la sanción fue común en la tragedia griega, los folletines, la soap opera, etc. Se ha utilizado en la serialidad televisiva, en la cinematográfica, en la literatura y en la narrativa oral (Paz Gago, 2004, p. 211). Cuanto más largo es el producto, más posibilidades hay de fragmentar la trama con analepsis de resolución parcial, siempre supeditadas al objetivo final del procedimental, de descubrir la identidad del asesino. La dilación como recurso se puede observar en varias ficciones del periodo analizado, como sucede, por ejemplo, en Desaparecida.

\section{Fragmentación espacial}

Un cambio sustancial en las producciones del periodo analizado consiste en la progresiva incorporación de imágenes exteriores, cada vez más sofisticadas. Las imágenes de acción policial, más o menos trepidante según la producción (Policías, Cuenta atrás, Los hombres de Paco, Soy el solitario), se mantienen como regularidad genérica, y van incorporando recursos (planos aéreos, cenitales, picados, contrapicados, efectos especiales) que las mantienen alejadas de aquellas primeras series en las que la acción siempre se desarrollaba en Madrid, sede de la mayoría de las productoras de la época (Brigada Central, Pájaro en una tormenta, Petra Delicado).

\section{Narración}

Otras técnicas narrativas que contribuyen a la fragmentariedad del relato son el contrapunto, la técnica Rashomon, mediante las cuales varias historias se cuentan simultáneamente o una misma historia se cuenta desde diferentes puntos de vista. También encontramos el recurso in media res en Cuenta atrás, Petra Delicado (1.10, "Mal día, el lunes"), El comisario (1.6, "Ojo por ojo"), Desaparecida (cap. 13 "El último día”). Estas figuras narrativas se observan también en algunas series estadounidenses relevantes de género dramático, por ejemplo, CSI, El ala oeste de la Casa Blanca (The West Wing, NBC, 1999-2006), Mujeres desesperadas (Desperate Housewives, ABC, 2004-2012) y House (House M.D., Fox, 2004-2012) (Tous-Rovirosa, 2008).

\section{Inserts en la estructura enunciativa}

El insert aporta dinamismo y resulta atractivo. Se convierte en el motor del flujo televisivo (Casetti y Odin, 1990, p. 19). La tipología de inserts que pueden contener las producciones analizadas es amplio, y constata la incorpo- 
ración de elementos relacionados con las nuevas tecnologías y de recursos cinematográficos que aumentan la espectacularidad y variedad de imágenes. La utilización de las tecnologías de la información propicia la condensación del tiempo (Hispano, 2006, p. 27), que favorece el aumento de la complejidad de las tramas y el intento de elaborar un esquema narrativo en el que las distintas tramas se presenten en aparente simultaneidad, como un tapiz. CSI, y en cierta medida también sus epígonos españoles, acentúa el desorden y la fragmentariedad narrativos mediante las tecnologías de la información y de la comunicación (TIC), en parte causantes del aumento de complejidad de las tramas. El ejemplo paradigmático de la utilización del recurso de simultaneidad es la serie 24, en la que la acción se desarrolla en tiempo real, con la ayuda de la pantalla partida. En Cuenta atrás, el juego con la temporalidad del relato se muestra con las sobreimpresiones de la hora en un reloj digital.

A continuación, presentamos una propuesta de clasificación de los inserts televisivos que fragmentan las ficciones analizadas, con cuatro categorías y catorce subcategorías (figura 1).

\section{Figura 1. Tipología de inserts de la serialidad policiaca en España (1990-2010).}

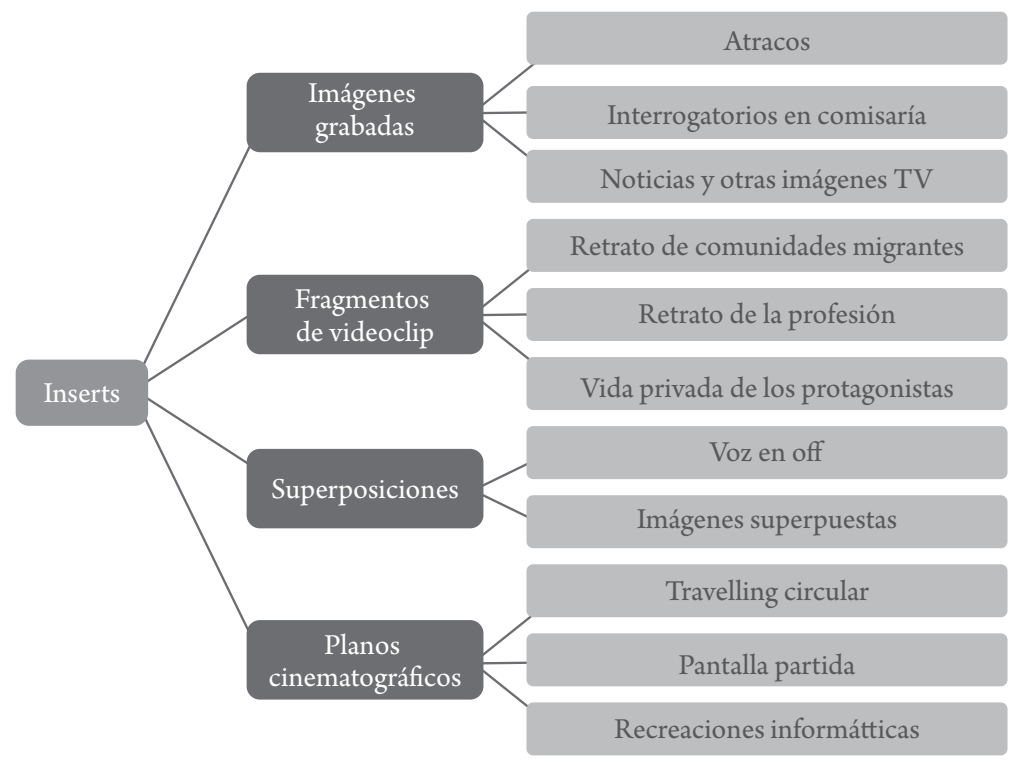

Fuente: elaboración propia. 


\section{Desenlace}

En referencia a la estructura, y por la relevancia de los finales para con el procedimental, destacamos que el desenlace puede presentar variaciones. El cliff-hanger (Los hombres de Paco, 5.1. "El click") aporta dosis de continuidad, ya sea relativo a la trama profesional, ya sea relativo a la sentimental. Dicha continuidad aumenta cuando se produce la desaparición de la resolución del caso en el episodio (Los hombres de Paco, 5.5. "La noche del comisario"). En caso de que se mantenga la resolución del caso policiaco, se puede producir continuidad en las tramas personales. También encontramos casos de estructura circular (Los hombres de Paco, 5.1. "El click"). Los tres casos se hallan en Los hombres de Paco y son novedosos en el género policiaco y antitéticos en relación con el planteamiento tradicional del procedimental.

Recapitulando, las principales tendencias narrativas en cuanto al relato fragmentado resultante pueden ser de:

1. Mosaico, pastiche: Este nuevo modo de relatar afecta prácticamente la totalidad de series posteriores a 2000 (El comisario, Policías) y a 2005 (Los hombres de Paco, Desaparecida, Cuenta atrás, Génesis, RIS Cientifica, Hermanos y detectives, Soy el solitario, La chica de ayer), así como la mayoría de las producciones unitarias (Fago, El caso Wanninkhoff) (tabla 1).

2. Espectacularización de las tramas de acción (Cuenta atrás, Soy el solitario, Los hombres de Paco).

3. Procedimental versus serialización y continuidad: A pesar de todo, la mayoría de las producciones mantienen la resolución del caso en la finalización del episodio, a excepción de Desaparecida y Los hombres de Paco. A veces, puede ser necesaria una segunda parte (Soy el solitario, UCO).

4. Subgénero forense (Génesis, RIS Científica): El subgénero forense incorpora unas determinadas características en relación con la fragmentariedad del relato (fragmentos de videoclip de retrato de la profesión, analepsis informativas y coloración de las analepsis, recreaciones informáticas) que provienen del hipotexto (la franquicia CSI) y se usarán tanto en las series propiamente forenses como en El comisario. El 
subgénero forense no tuvo buenos resultados de audiencia (Génesis: 5,66 \% de share; RIS Cientifica: $15 \%$ de share). Recordemos que en el periodo analizado (era previa a la actual fragmentación de la audiencia) el share adecuado para la pervivencia de un programa televisivo era del $20 \%$. En relación con el conjunto de las series policiacas del periodo, se observa mayor fortuna en la adopción del subgénero forense dentro de un producto de éxito y para todos los públicos, como El comisario en la adaptación de series especializadas de dicho subgénero, mediante los personajes de Rita Carvajal (Charo Zapardiel), que más adelante será sustituida por Sara Ruiz (Cristina Castaño). Carvajal hace alguna broma intertextual refiriéndose a la citada serie estadounidense. ${ }^{15}$

5. El recurso visual a fragmentos de videoclip (Tous-Rovirosa, 2008, p. 104), propio de algunas producciones estadounidenses, se propaga más allá del subgénero forense, hasta el drama de profesiones que es el policiaco del periodo analizado. Su uso y función puede ser idéntico al del hipotexto: en CSI, RIS Científica y Génesis, se usa con función divulgativa para describir la minuciosa tarea profesional de los agentes; o puede variar: en Los hombres de Paco, pueden no estar asociados a la acción policial y son frecuentes y largos; y en El comisario, a menudo con un color diferenciado, como las analepsis en otras producciones, para retratar a comunidades migrantes, en las primeras temporadas recurriendo a estereotipos negativos que evolucionan hacia el final de la serie. ${ }^{16}$

\section{Hibridación genérica}

La hibridación genérica es un rasgo característico de las producciones audiovisuales de la primera década de 2000, y se observa especialmente en las tres series más relevantes del periodo. El género hospitalario se imbrica con frecuencia en las tramas de Policías, en el corazón de la calle, en parte por la presencia casi continuada del Servicio de Asistencia Municipal de

15 Rita: "Me voy pitando que ponen CSI" (El Comisario, 8.9, "Cuatro balas").

16 Sobre la evolución de la representación de los migrantes en El comisario véase Lacalle (2008). Observamos que hacia el final de la serie la representación de las comunidades migrantes mediante los fragmentos de videoclip tiene una sanción positiva, mostrando actividades cotidianas (parque infantil o prácticas deportivas, por ejemplo, en "Asomarse al abismo", 10.9, El comisario. 
Urgencias y Rescates (Samur). Diferenciamos entre la hibridación hospitalaria por regularidad genérica obligatoria (Ryan, 1979), necesaria para la trama, ya que algunas de las escenas se tienen que desarrollar parcialmente en hospitales, y la regularidad genérica opcional o independiente. Observamos el uso "obligatorio" en Cuenta atrás, El comisario, Desaparecida, etc. Pero la hibridación genérica "opcional" o "independiente" acentúa la mezcla de géneros, de modo que en El comisario se producen escenas del denominado action crime (Buonanno, 2001) en un hospital, hasta el extremo de que una enfermera se queje de las agresiones sufridas en este por parte de delincuentes (El comisario, 8.9. "Cuatro balas"). Paralelamente, el drama hospitalario español de la época se hibrida con la acción policial. En Los hombres de Paco, el género hospitalario aparece desde la primera temporada, con la comicidad y tono esperpéntico propios de esta serie (Los hombres de Paco, 1.4. "Operación Pikachu"), en algún caso incorporando un musical hospitalario (Los hombres de Paco, 5.1. "El click"). En cambio, el género legal, tradicionalmente más vinculado al policiaco por razones obvias, solo aparece en Lobos (Antena 3, 2005), en El caso Wanninkoff (TVE 1,2008) y esporádicamente en algunos episodios de algunas de las series analizadas. ${ }^{17}$

\section{Influencias extranjeras}

Brigada Central, protagonizada por Imanol Arias, es la primera serie policiaca española, tras la coproducción Eurocops. Recibe una clara influencia de Canción triste de Hill Street, que se emitió en TVE 1 entre 1987 y 1988, un año antes del inicio de la serie española (Contreras, 1988). Los diálogos en comisaría rápidos y vibrantes, y la estética cinema verité, dan cuenta de esa influencia (cfr. Zunzunegui y Zubillaga, 1988). Los casos suelen tener un punto sórdido. Canción triste de Hill Street es un precedente televisivo fundamental en el uso de la multiplicidad de tramas por episodio (Álvarez, 1999; Cooke, 2001), cuya influencia se pudo observar más adelante en series como Urgencias (ER, NBC, 1994-2009) o El ala oeste de la Casa Blanca.

Cuatro se incorpora al género policiaco en 2005, el mismo año de inicio de emisiones de la cadena, con la fallida Suárez y Mariscal: caso cerra-

17 El comisario, Petra Delicado (1.6, “Tu muerte está cerca”), Policías en el corazón de la calle ("Mateo y Rafa”) y RIS Científica. 
do (Cuatro, 2005), Génesis: en la mente del asesino (Cuatro, 2006-2007) y Cuenta atrás (Cuatro, 2007-2008). La apuesta de la nueva emisora como cadena moderna e innovadora en España se puede relacionar (además de las emisiones de Friends, NBC, 1994-2004) con el hecho de que las tres producciones del nuevo canal reciben una clara influencia de series extranjeras: Suárez y Mariscal es una adaptación de la alemana Niedring und Kuhnt, que presenta algunas características interesantes (aunque en términos de audiencia fracasó con un 3,97\% de share), ya que es el único serial del conjunto de ficciones analizadas y también la única producción que no estuvo protagonizada por actores profesionales; Génesis pertenece al subgénero forense inaugurado por la estadounidense CSI: Las Vegas (CSI: Crime Scene Investigation, CBS, 2000-2015), pero con importantes similitudes también de la psicología criminal y la antropología de Bones (Fox, 2005-2017); Cuenta atrás presenta similitudes con la también estadounidense 24 (Fox, 2001-2010), especialmente en relación con la temporalidad del relato. La serie protagonizada por el cantante Dani Martin en el papel de Corso, un policía suficientemente heterodoxo para ser caracterizado de pícaro o granuja, al margen de la ley (rogue cop, outlaw cop), va dirigida a un espectador adulto, $y$ con estas influencias presenta la que probablemente sea una de las producciones más dinámicas del periodo, con un ritmo trepidante, mucha acción policial y mucha tensión, así como recursos visuales sofisticados (planos cenitales, picados y contrapicados), pero no obtuvo buenos resultados de audiencia (10,1\% de share). En ocasiones, se muestra también cierta brutalidad policial (Cuenta atrás, Piloto, "Bosque del olvido", 18:40 horas). La estructura en analepsis de la serie es la influencia más evidente de 24. La narración "en tiempo real" en el transcurso de una hora se resalta mediante la sobreimpresión del reloj digital en pantalla. La pantalla partida es un recurso visual que se usa en estas dos series y de un modo más puntual también en Policías, UCO y Génesis (por ejemplo, en 1.1. "Los desastres de la guerra").

En relación con las series forenses, ya se ha mencionado que la de Cuatro tuvo una audiencia mucho menor que RIS Cientíica (Tele 5, 2007), una adaptación de la italiana RIS: Delitti imperffetti, que se inspira a su vez en la mencionada CSI. A parte de otros motivos (Génesis es probablemente 
la serie más psicológica y con menos acción del conjunto), cabe recordar que Cuatro se encontraba en sus inicios y era una cadena con un share mucho menor del resto. RIS se muestra parecida a CSI desde los créditos iniciales.

Las demás producciones a partir de 2005 van introduciendo características y recursos extranjeros de índole diversa, hasta llegar a otra adaptación: La chica de ayer (Antena 3, 2009) de Life on Mars (BBC One, 2006-2007), una reinvención del policiaco mediante el salto temporal, que tuvo éxito de público y de crítica. El resultado en el caso español fue una "amable relectura de la Transición"; una visión "optimista y tranquilizadora del proceso" (Cascajosa, 2012, p. 266), con visos de comicidad mediante el contraste entre las dos eras (1977 y 2009).

\section{Conclusiones}

La serialización del género policiaco, la sofisticación en el uso de recursos narrativos y visuales y una clara influencia de las producciones estadounidenses (también anglosajonas y alemanas) determinan la evolución del periodo analizado que se constata en la hibridación genérica y de formato, el subgénero forense y los recursos narrativos. El análisis aquí realizado mostró que la influencia de las ficciones de otros países funciona mejor en la medida en que se van introduciendo como elementos del relato en las producciones nacionales. La adaptación de producciones extranjeras no acostumbra a significar una mejora en los resultados de audiencia, excepto el caso de La chica de ayer. Es necesario destacar el caso de Mariscal y Suárez, el único serial del periodo que fracasó mientras que las ficciones seriadas iban incorporando características de serialización.

Parafraseando a Buonanno (2006), no solo "los temas viajan", sino también los formatos y géneros, y sus respectivas evoluciones. Del mismo modo, se observa mayor éxito en la adopción del subgénero forense dentro de un producto de éxito y para todos los públicos como El comisario que en la adaptación de series especializadas de este subgénero. De ahí se infiere cierto conservadurismo en las producciones para todos los públicos, y una limitada voluntad de arriesgar de las cadenas y productoras de la época. La evolución a lo largo de los veinte años de análisis constata un 
profundo cambio en los recursos narrativos y visuales, y deja atrás el cinema verité de Brigada Central o la preeminencia del telling en detrimento del showing en Petra Delicado, así como una construcción del relato mediante una cantidad menor de tramas entrelazadas respecto de las producciones posteriores. En parte, este cambio se explica por la progresiva sustitución de las adaptaciones literarias y coproducciones por influencias extranjeras.

La hibridación de formato propia del periodo analizado se constata en que era el género episódico por excelencia. Tras los inicios (Brigada Central, Eurocops, Petra Delicado, Pepe Carvalho) en el conjunto de series analizadas, especialmente a partir de 2000, se lleva a cabo un aumento de la fusión de lo personal y lo profesional que va de la mano de la serialización en las tramas, que llega, incluso, al extremo de los recordatorios propios de la soap opera, cliff-hangers, fragmentos de videoclip de la vida privada, analepsis emotivas, etc. Muchos de los recursos procedentes de las series forenses se usan para propósitos relativos a la serialización. La serialización coincide con el establecimiento del género policiaco en España en la segunda década analizada (2000-2010). La resolución del caso depende de las analepsis, de ahí el carácter completivo de esta figura retórica en el policiaco. Este es el mecanismo que permite que el procedimental y el serial se articulen, $y$ que el policiaco se mantenga como género en auge en la ficción televisiva contemporánea y propicie títulos a las nuevas y viejas plataformas.

Las resoluciones de enigmas propias del género policiaco se introducen en otras narrativas (Perdidos, The Americans, Orange is the New Black o, incluso, la comedia How I met your mother) para elaborar un relato cuya duración real va a depender del éxito del producto y va a condicionar la cantidad de analepsis de resolución. Las fases de competencia y performancia del esquema narrativo canónico (Greimas, 1983) se prolongan; la sanción depende de la respuesta de la audiencia. El mosaico de tramas entrelazadas se ha convertido en una fórmula televisiva, especialmente de la ficción seriada, con Canción triste de Hill Street como precedente. La narrativa contemporánea, también la cinematográfica, desde hace años trenza las tramas como si de un puzle se tratara (Syriana, Stephen Gagan, 2005; Babel, Alejandro González Iñárritu, 2006; Nine Lives, Rodrigo García, 2005; Loggerheads, Tim Kirkman, 2005), etc. (Tous-Rovirosa, 2008). 
La auténtica revolución de la ficción televisiva reciente consiste en vincular serialidad y calidad. Este nexo se origina en la década de los noventa con Twin Peaks (ABC, 1990-1991) y Expediente X (The X Files, Fox: 19932002) (Tous-Rovirosa, 2008, p. 121), y se acrecienta mediante los mecanismos observados en este artículo. El uso de la analepsis se generalizará en la ficción televisiva. El pastiche que resulta del uso de distintas figuras retóricas en distintos ámbitos, literarias, cinematográficas o televisivas, conlleva la fragmentariedad del discurso y la hibridación genérica. La fragmentación visual de la trama acentúa una narrativa posmoderna como consecuencia de la ausencia de relatos épicos. Del mismo modo que en la novela artúrica, en la narrativa contemporánea, "las aventuras particulares y los entrelazamientos están al servicio de la creación de una forma intensamente cohesionada" (Cirlot, 2005, p. 183). En la interrelación (entrelazamiento) y en la estructura de la búsqueda con la pregunta para desvelar la verdad (queste), íntimamente unidas, el policiaco se reafirma en la desesperada tarea de combatir inútilmente el mal (Von Mueller, 2014; Cirlot, 2005). La adopción de estas características a nivel internacional produce una narrativa en el género policiaco cada vez más homogénea entre la ficción española y estadounidense, como se puede observar en ficciones recientes como La casa de papel (Netflix, 2017-). Las alteraciones temporales y la fragmentación del relato aquí analizadas producen ficciones parecidas a un mosaico, a la vez que estas transformaciones narrativas se usan para aumentar la vinculación de un espectador más activo, el engagement, que permite relacionar la narrativa audiovisual con los videojuegos. La complejidad del relato facilita la creación de mundos nuevos (narrativa transmedia) y la aceleración, inmediatez y rapidez (Tomlinson, 2007) se producen no solo en el relato de ficción, sino también en el informativo. Se abre un conjunto de temas que pueden ser objeto de nuevas líneas de investigación.

\section{Referencias}

Agger, G. (2016). The development of transnationality in Danish noirfrom unit one to the team. Northern Lights: Film \& Media Studies Yearbook, 14(1), 83-101. https://doi.org/10.1386/nl.14.1.83_1

Allen, R. \& Berg, T. (2014). Serialization in Popular Culture. Routledge. 
Álvarez Berciano, R. (1999). Series norteamericanas: la fórmula deléxito. En L. Vilches, Taller de escritura para televisión. (pp. 229-261). Gedisa.

Bal, M. (2005). Narratology: Introduction to the theory of narrative. University of Toronto Press.

Balló,J. \& Pérez,X. (2005).Jo ja he estat aquí:ficcions de la repetició. Empúries.

Bordwell, D. (1996). La narración en el cine de ficción. Paidós.

Buonanno, M. (2001). The European television industry at the turn of the XXI century. En Eurofiction Fifth Report, 2000. (pp. 1-28). European Audiovisual Observatory. https://www.researchgate.net/ publication/321805781_The_European_television_industry_ at_the_turn_of_the_XXI_century_EUROFICTION_FIFTH REPORTyear_2000_European_Audiovisual_Observatory_ Strasbourg_2001

Buonanno, M. (2005). La masa y el relleno: la miniserie en la ficción italiana. De Signis, 7-8, 19-30. http://www.designisfels.net/revista/ los-formatos-de-la-television

Buonanno, M. (2006). Narrative in viaggio. Manuscrito no publicado, Universitat Pompeu Fabra.

Buonanno, M. (2018). Widening landscapes of TV storytelling in the digital media environment. Anàlisi: Quaderns de Comunicació $i$ Cultura, 58, 1-12. https://doi.org/10.5565/rev/analisi.3133

Casetti, F. \& Odin, R. (1990). De la paléo-à la néo-télévision. Communications, 51(1), 9-26. https://www.persee.fr/doc/comm_05888018_1990_num_51_1_1767?pageid=t1_26

Casetti, F. y Di Chio, F. (1991). Cómo analizar un film. Paidós. 
Cascajosa Virino, C. (2012). La chica de ayer: memoria y desmemoria televisivas de la Transición en España. Journal of Spanish Cultural Studies, 13(3), 260-275. http://dx.doi.org/10.1080/14636204. 2013.788913

Cascajosa Virino, C. (2015). Formas y contenidos: las estructuras narrativas de la ficción televisiva en España. En B. Puebla Martínez, N. Navarro Sierra y E. Carrillo Pascual (Coords.), Ficcionando en el siglo XXI: la ficción televisiva en España. (pp. 15-32). Icono 14.

Cascajosa Virino, C. (2018). Un nuevo sentido del lugar: las narraciones del sur y la geopolítica en el proceso de renovación de la ficción televisiva española de género criminal. Arbor, 194(789), a473. https:// doi.org/10.3989/arbor.2018.789n3015

Cuadrado, A. (2016). Series de TV y videojuegos: la poética de la serialidad en la forma lúdica. Anàlisi: Quaderns de Comunicació i Cultura, 55, 17-30. http://dx.doi.org/10.7238/a.v0i55.2896

Chalaby, J. K. (2016). Drama without drama: The late rise of scripted TV formats. Television \& New Media, 17(1), 3-20. https://doi. org/10.1177/1527476414561089

Cirlot, V. (2005). Figuras del destino: mitos y símbolos de la Europa medieval. Siruela.

Colmeiro, J. (1994). La novela policiaca en España: historia y crítica. Anthropos.

Contreras, J. M. (1988, enero 5). 'Canción triste de Hill Street' regresa a TVE. El País. https://elpais.com/diario/1988/01/06/radiotv/568422003_850215.html

Cooke, L. (2001). The police series. En G. Creeber (Ed.), The television genre book. (pp. 19-23). British Film Institute. 
Crisóstomo Gálvez, R. \& Ros Zofío, E. (2014). Television cosmo-mythologies: The return to mythological naratives in television fiction, from The Prisoner to Lost. En V. Marinescu, S. Branea \& B. Mitu (Eds.), Critical reflections on audience and narrativity: New connections, new perspectives. (pp. 103-117). Verlag.

Duch, L. (1995), Mite i cultura. Publicacions de l’Abadia de Montserrat.

Fiske, J. (1987). Television culture. Metheun.

Galán-Farjardo, E. y Rueda-Laffond, J. C. (2011). Narrativizando la historia: un enfoque interdisciplinar aplicado al relato televisivo. Palabra Clave, 14(1), 85-99. https://doi.org/10.5294/pacla.2011.14.1.5

García, A. N. (2016). A storytelling machine: The complexity and revolution of narrative television. Between, 6(11). http://dx.doi. org/10.13125/2039-6597/2081

García-Fanlo, L. (2017). El lenguaje de las series de televisión. Eudeba.

Garin Boronat, M. (2017). Heridas infinitas: estructura narrativa y dinámicas seriales en la ficción televisiva. L'Atalante, 24, 27-41. http:// www.revistaatalante.com/index.php?journal=atalante\&page $=$ arti cle\&op=view\&path $\% 5 B \% 5 \mathrm{D}=414$

Genette, G. (1972). Figures III. Seuil.

González Requena, J. (1992). El discurso televisivo: espectáculo de la posmodernidad. Cátedra.

Greimas, A. J. (1983). La semiótica del texto: ejercicios prácticos. Paidós.

Gubern, R. (1999). Los personajes serializados. En V. Benet y E. Nos (Eds.), Cuerpos en serie. (pp. 15-20). Universitat Jaume I. 
Innocenti, V. y Pescatore, G. (2011). Los modelos narrativos de la serialidad televisiva. La balsa de la medusa: Revista cuatrimestral de críticay humanidades, 6, 31-50. https://www.academia.edu/5744975/ Los_Modelos_narrativos_de_la_serialidad_televisiva

Hispano, A. (2006, febrero 1). Una telaraña de destinos cruzados. La Vanguardia.

Imbert, G. (2003). El zoo visual: de la televisión espectacular a la televisión especular. Gedisa.

Imbert, G. (2005). De lo grotesco como contaminación de los géneros en los nuevos formatos televisivos. DeSignis, 7-8, 0159-170. https:// ddd.uab.cat/record/208142

Jacobs, J. (2001). Hospital Drama. En G. Creeber, The television genre book. (pp. 23-26). British Film Institute.

Jacobs, J. (2003). Body trauma TV: The new hospital dramas. British Film Institute.

Jost, F. (2005). Lógicas de los formatos de tele-realidad. DeSignis, 7-8, 53-65. http://www.designisfels.net/revista/los-formatos-de-la-television

Klinger, B. (2018). Gateway bodies: Serial form, genre, and white femininity in imported crime TV. Television \& New Media, 19(6), 515534. https://doi.org/10.1177/1527476418768003

Lacalle, C. (2008). El discurso televisivo sobre la inmigración. Omega.

Ley $7 / 2010$, de 31 de marzo, general de la comunicación audiovisual. BOE, núm. 79 (2010).

Lindner, C. (2014). The serial drive. En R. Allen \& T. Van den Berg (Eds.), Serialization in popular culture. (pp.9-11). Routledge. 
Littleton, C. (2015, diciembre 16). Peak TV: Surge from streaming services, cable pushes 2015 scripted series tally to 409 . Variety. https://variety.com $/ 2015 / \mathrm{tv} /$ news/peak-tv-409-original-series-streamingcable-1201663212/

Lyon, D. (1994/1996). Posmodernidad. Alianza.

Lyotard, J. F. (1979). La condition postmoderne: Rapport sur le savoir. Les éditions de Minuit.

Lyotard, J. F. (1993). Defining the postmodern. En S. During (Ed.), The cultural studies reader. (pp. 170-175). Routledge.

Magris, C. (1984). L'anello di Clarisse: grande stile e nichilismo nella letteratura moderna. Einaudi.

McCarthy, A. (2001). Studying soap opera. En G. Creeber, The television genre book. (pp. 47-49). British Film Institute.

Mittell, J. (2004). Genre and television: From cop shows to cartoons in American culture. Routledge.

Mittell, J. (2006). Narrative complexity in contemporary American television. The Velvet Light Trap, 58(1), 29-40. https: //doi.org/10.1353/ vlt.2006.0032

Mittell, J. (2009). All in the game: The Wire, serial storytelling, and procedural logic. En P. Harrigan \& N. Wardrip-Fruin (Eds.), Third person: Authoring and exploring vast narratives. (pp. 429-438). Massachussets Institute of Technology.

Mittell, J. (2015). Complex TV: The poetics of contemporary television storytelling. New York University Press.

Mueller, E. von. (2014). The police procedural in literature and on television. En C. R. Nickerson (Ed.), The Cambridge companion to American crime fiction. (pp. 96-109). Cambridge University Press. 
Nelson, R. (1997). Flexi-narrative from hill street to holby city. En TV drama in transition: Forms, values and cultural change. (pp. 30-49). Palgrave Macmillan.

Newcomb, H. (1974). TV: The most popular art. Anchor Books.

Newman, M. Z. \& Levine, E. (2012). Legitimating television: Media convergence and cultural status. Routledge.

Paz Gago, J. M. (2004). Propuestas para un replanteamiento metodológico en el estudio de las relaciones entre literatura y cine: el método comparativo semiótico-textual. Signa: Revista de la Asociación Española de Semiótica, 13, 199-232. http://e-spacio.uned.es/revistasuned/index.php/signa/article/viewFile/6095/5830

Pérez López, H. J. (2011). Introducción al presente número "nueva narrativa: la ficción serial televisiva”. La balsa de la Medusa, 6, 5-12.

Pérez,X. (2011). Las edades de la serialidad. La balsa de la Medusa, 6, 13-30.

Pérez, X. y Garin Boronat, M. (2013). La narrativa artúrica como modelo para la escritura de series televisivas: perspectivas históricas y formales. Historia y Comunicación Social, 18(3), 587-99. https://revistas.ucm.es/index.php/HICS/article/view/44268

Piñón, J. y Flores, A. (2017). Estados Unidos: el año de las superseries. En M. I. Vassallo de Lopes y G. Orozco Gómez (Coords.), Una década de ficción televisiva en Iberoamérica: análisis de diez años de Obitel (2007-2016). (pp. 257-289). Globo.

Raya Bravo, I. (2016). La tendencia hacia la hibridación en el macrogénero extraordinario durante la era hipertelevisiva. Casos de estudio: Galáctica: estrella de combate, Juego de Tronos y American Horror Story. Revista de la Asociación Española de Investigación de la Comunicación, 3(6), 11-18. https://doi.org/10.24137/raeic.3.6.2 
Rincón, O. (2011). Nuevas narrativas televisivas: relajar, entretener, contar, ciudadanizar, experimentar. Comunicar: Revista Científica Iberoamericana de Comunicación y Educación, 36, 43-50. https://dialnet.unirioja.es/servlet/articulo? codigo $=3639917$

Romero Santos, R. (2015). Mucha policía, mucha diversión: la ficción criminal en la ficción española. En B. Puebla Martínez, N. Navarro Sierra, N. y E. Carrillo Pascual (Coords.), Ficcionando en el siglo XXI: la ficción televisiva en España. (pp. 261-276). Icono 14.

Ros, E. (2011). Las series de ficción en la era de la post-TV. Fundación Taller de Guionistas.

Ryan, M. L. (1979). Toward a competence theory of genre. Poetics, 8(3), 307-337. https://doi.org/10.1016/0304-422X(79)90037-8

Smith, P. J. (2007). Crime scenes: Police drama on spanish television. Journal of Spanish Cultural Studies, 8(1), 55-69. https://doi. org/10.1080/14636200601148819

Steenberg, L. (2013). Forensic science in contemporary american culture: Gender, crime, and science. Routledge.

Tomlinson, J. (2007). The culture of speed: The coming of immediacy. Sage.

Torrado Peláez, D. (2017). La falacia dramática en la ficción televisiva nacional y su relación con los índices de audiencia: análisis del medio televisivo en términos de mercadotecnia. El caso de Los hombres de Paco (Tesis doctoral, Universidad de Sevilla). https://idus.us.es/bitstream/handle/11441/64351/TESIS \%20LA \%20FALACIA \%20 DRAM \%C3 \%81TICA.pdf?sequence=1

Tous-Rovirosa, A. (2008). El text audiovisual: anàlisi des d'una perspectiva mediològica (Tesis doctoral, Universidad Autónoma de Barcelona). 
Vernet, M. (1990). Incertain zapping. Communications, 51(1), 3344. https://www.persee.fr/doc/comm_0588-8018_1990_ num_51_1_1769

Vilches, L. (2008). Spain: The year of formats and migration. En M. I. Vassallo de Lopes \& L. Vilches (Coords.), Global markets, national stories. 2008 Obitel Yearbook. (pp. 260-289). Globo.

Vilches, L., Berciano, R. A., Lacalle Zalduendo, M. R., Algar León, S. y Polo Prados, S. (2000). Informe Eurofiction 1999: Menos familia y más policía. Zer: Revista de Estudios de Comunicación, 5(9), 2759. https://ddd.uab.cat/record/25030

Wallace, D. F. (2001). Et unibus pluram: televisión y narrativa americana. En Algo supuestamente divertido que nunca volveré a hacer. Grijalbo.

Wolf, M. (1984). Géneros y televisión. Anàlisi: Quaderns de Comunicació i Cultura, 9, 189-198. https://www.raco.cat/index.php/Analisi/ article/view/41275

Zunzunegui, S. y Zubillaga, J. (1988). Tengan mucho cuidado ahí dentro: Hill Street Blues o los variados matices del gris. Fundación Instituto Shakespeare. 